\title{
THE ROLE OF CONCURRENT SEXUAL RELATIONSHIPS IN THE SPREAD OF SEXUALLY TRANSMITTED INFECTIONS IN YOUNG SOUTH AFRICANS
}

\author{
Chris Kenyon, $M B C h B, B A$ (Hons), $M P H, F C P$ \\ Division of Infectious Diseases and HIV Medicine, Department of Medicine, University of Cape Town \\ Motasim Badri, MSc (Med) \\ Department of Medicine, University of Cape Town
}

\begin{abstract}
We still do not know why the HIV prevalence in southern and eastern Africa is an order of magnitude higher than anywhere else in the world. An article in this journal in 2007 argued that a key determinant was not so much the lifetime numbers of sexual partnerships, but rather the high proportion of these partnerships that are arranged concurrently. Concurrency has been associated with elevated rates of sexually transmitted infections (STIs) elsewhere, but this relationship has never been demonstrated in an African setting, where its effect is proposed to be greatest. We conducted a secondary data analysis from a representative survey of $14-25$-year-olds living in Cape Town to test the hypothesis that concurrency is associated with self-reported symptoms of an STI. On logistic multiple regression analysis we found a modest but statistically significant relationship between self-reported STI symptoms and having had a partner who engaged in concurrency.
\end{abstract}

The traditionally measured sexual behaviour risk factors are only able to explain some of the elevated HIV prevalence in southern/eastern Africa. For example, the most comprehensive international study of differences in sexual practices around the world, based on demographic and health surveys and other data, concluded that men and women in sub-Saharan Africa typically have a similar or lower number of lifetime partners than do their heterosexual counterparts elsewhere. 'Similarly, within Africa the prevalence of risky behaviours was unable to explain the difference in HIV spread between western and eastern/southern Africa. ${ }^{2}$

What then are the current explanations for the high HIV prevalence in southern/eastern Africa? A recent joint inquiry by the Southern African Development Community and UNAIDS concluded that 'high levels of multiple and concurrent sexual partnerships by men and women, with insufficient, correct condom use, combined with low levels of male circumcision are the key drivers of the epidemic in the (Southern African) region'. The putative mechanisms for how concurrency could be such a driving force in HIV spread are outlined in Box 1 and Fig. 1. Concurrency may be defined as sexual partnerships overlapping in time, when one partnership starts before another terminates. Outside of sub-Saharan Africa, concurrency has been shown to play an important role in the spread of STIs such as syphilis, ${ }^{3}$ gonorrhoea, ${ }^{4}$ chlamydia ${ }^{5}$ and HIV. ${ }^{6}$ However, within Africa a sero-linked study found no link between concurrency rates and HIV transmission. ${ }^{7}$ Numerous problems with this study have been raised (reviewed in $\mathrm{Mah}^{8}$ ). There are ecological data to support the link between HIV and concurrency. A World Health Organization-conducted international comparative study found that concurrency rates were considerably higher in sub-Saharan Africa (18 - 55\%) than in other Third-World areas such as South Asia (2 $3 \%$ ) which had lower HIV rates. ${ }^{9}$ Very few studies of the prevalence and effects of concurrency in South Africa have been done. A survey in rural KwaZulu-Natal found that $40 \%$ of sexually active men reported having had more than one partner in the past 3 months, and it was considered likely that many of these were concurrent. ${ }^{10}$ A study of 15 - 26-year-olds in the Eastern Cape found that $55 \%$ of young men had engaged in one or more concurrent relationships in the past. ${ }^{11} \mathrm{~A}$ household survey in Khayelitsha, Cape Town, found that 29\% of men and $8 \%$ of women in sexual relationships reported that they had been sexually involved with individuals from outside their regular relationship in the last 12 months.

The Cape Area Panel Survey (CAPS) is one of the first surveys to collect detailed information on respondent and partner concurrency. A secondary data analysis of the 


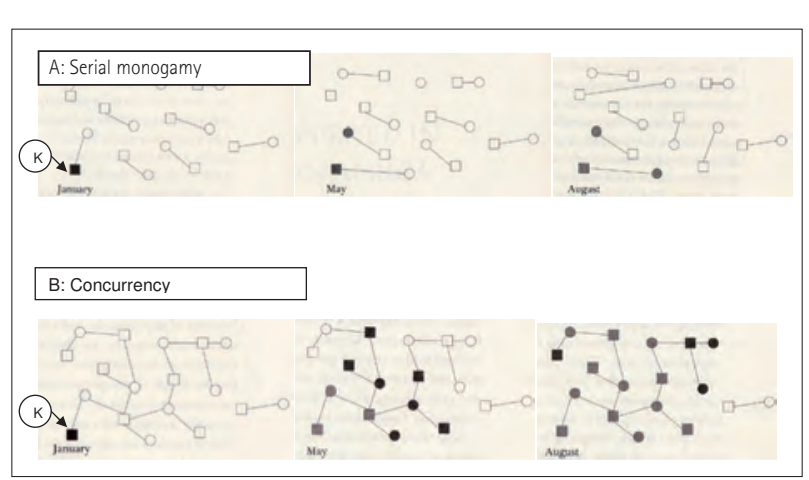

Fig. 1. The effect of sexual network configuration on HIV transmission in two hypothetical populations with the same number of lifetime partners, but differing concurrency patterns. Population A has a pattern of serial monogamy, while most of population $B$ are connected in a concurrent network. In both populations individual $\mathrm{K}$ (bottom left) contracts HIV in January. In A, the individual will have a high probability of transmitting the infection on to his January partner while in seroconversion and then a lower probability of passing it on to his next partners. The future partners of $K$ 's infected January partner are also less likely to be infected owing to the reduced chances of their having sex during seroconversion. In $B$, the virus spreads rapidly through the network, as each person who becomes infected has a much higher probability of transmitting the virus on to another partner due to the fact that they are much more likely to have sex with the other partner/s during the seroconversion period (diagram based on one by Epstein H. 2008. The Invisible Cure: Africa, the West and the Fight against AIDS. Picador, 2008, reproduced with permission).

CAPS dataset found that 38\% of black females (versus $14 \%$ of other racial/ethnic groups) report that at least one current or previous partner definitely had another sexual relationship during their relationship. The corresponding figures for males are 28\% for blacks and 10\% for the others. Turning to whether or not the respondent ever had two simultaneous sexual relationships, this was the case for $41 \%$ of black males, and $4 \%$ and $21 \%$ for white and coloured males, respectively (Kenyon $\mathrm{C}$ et al. - unpublished data).

CAPS is not an HIV-serolinked study, but it did collect information on whether or not the respondent had symptoms of an STI in the past 12 months. Since there are numerous studies in Africa (and elsewhere) showing that self-reported symptoms of genital discharge and ulcers are associated with HIV infection, ${ }^{12-14}$ we conducted a multivariate logistic regression analysis to test the hypothesis that concurrency is associated with STI symptoms.

\section{DATA AND METHODS}

We analysed data from the CAPS dataset to determine the distribution, prevalence and correlates of symptoms of STIs. CAPS is a representative longitudinal study of adolescents aged $14-22$ living in Cape Town:15 4752 adolescents were interviewed in the first wave in 2002 and in the second wave in 2004. In the third wave, conducted in 2005, 3324 of the initial 4752 individuals were re-interviewed. All of our analyses are weighted with sampling weights correcting for sample design and appropriate wave non-response. Applying these weights, coloureds comprised 59\% of the total wave 1 sample, blacks 15\% and whites 26\%. As seen in Table I, the attrition rates between 2002 and 2005 were considerably higher for whites (53\%) than for blacks (36\%) and coloureds (21\%). The lower response rate for whites is typical of survey results in South Africa. ${ }^{12}$ Participants were interviewed about their socio-demographic, education, employment, health ailments and sexual behaviour histories. Unfortunately questions pertaining to previous STI symptoms were only asked in wave 1 (2002) and detailed sexual behaviour histories were only investigated in wave 3 (2005). The analyses presented here were restricted to all persons who were sexually active in wave 1 and completed the wave 3 questionnaire - a total of 1482 respondents.

We examined the association of STI symptoms with various socio-demographic and sexual behaviour variables which we chose on the basis of our conceptual framework for understanding the spread of STIs (Fig. 3). The socio-demographic variables included age, educational attainment, wealth quintile, ethnic/race group, alcohol consumption in the last month, knowledge about STI prevention strategies, marital status and general mental state. The sexual behaviours evaluated were age at first sexual intercourse, lifetime number of sexual partners, an age gap of 4 or more years between sexual partners, condom use at last sex, ever pregnant, and partner or respondent ever engaged in a concurrent relationship. Risk factors that were found to be associated with symptoms of an STI at a significance level of $p<0.10$ were included in the logistic regression analysis.

Analyses were conducted in STATA Version 10, utilising the survey methodology to adjust for the complex two-stage survey design. When appropriately weighted for over-sampling of blacks and whites, as well as nonresponse, the results are representative of metropolitan Cape Town. Univariate and multivariate logistic regression was utilised to evaluate the strength of the association between STI symptoms and the independent variables.

\section{RESULTS}

Table II depicts the ongoing socio-economic deprivation of blacks and to a lesser extent coloureds, as measured in terms of income, educational attainment, parental employment and whether or not the youth live with their parents.

In univariate analysis, the following were positively associated with STI symptoms: being female, black, coming from the poorest 20\% of the population, poor educational outcomes, knowing someone who has died of HIVIAIDS, having consumed alcohol in the last month, ever been pregnant, ever been forced or hurt during sex, having a first sex partner who was 4 or more years older, having had a partner who had another concurrent re- 


\section{How does concurrency enhance HIV transmission?}

Concurrent relationships result in an exponential acceleration of HIV transmission due to two main factors. Firstly, concurrency has a dramatic effect on increasing the size of the 'connected component' - the number of persons who are directly or indirectly sexually connected at any point in time. Morris and Kretzschmar modelled the spread of HIV in two populations, one characterised by serial monogamy and the other by long-term concurrency. ${ }^{6}$ They modelled this in a way that kept the total number of sexual relationships the same in the two populations. Despite this, the HIV prevalence after 5 years was 10 times higher in the population with concurrency, and the key mediating factor was the increased size of the concurrency-induced connected component. In a serial monogamy setting this component can never be greater than 2, but in situations of concurrency this number can be very large and the virus is therefore not trapped in a monogamous relationship after transmission. If we consider that HIV transmissibility is enhanced 10 - to 40 -fold in the acute infection phase, ${ }_{1}^{24-26}$ then in a network characterised by concurrency, as soon as one person is infected everyone else in the connected component is at dramatically increased risk. By way of contrast, in serial partnerships, because of the monogamy during the relationship and the gaps between relationships, a recently infected person is less likely to expose another partner during this short high-viraemia-risk period and by definition is unable to expose a whole connected component of the population. If Kretzschmar and Morris had included this dramatically elevated HIV transmission rate during early disease in their analysis, then the modelled impact of concurrency would have been considerably greater. ${ }^{27}$ Secondly, the infection-transmission-lowering effect of 'partner-sequencing' is lost. ${ }^{28}$ These dynamics are il- lustrated in Fig. 2, which compares a serial monogamy dynamic with a concurrent sex network. In both, individual $A$ has 5 partners and is exposed to HIV by his third partner, D. In the concurrency network, A is able to infect all 4 other partners with a relatively high probability during his seroconversion period - or as many as he has sexual relationships with during this period. In the serial monogamy network, $\mathrm{C}$ and $\mathrm{B}$ are protected by 'partner-sequencing', and only $\mathrm{E}$ is at high risk of HIV infection and even then only if the $A$ - $E$ relationship occurs before A's seroconversion period is over. $F$ is at lower risk of HIV acquisition - approximately $1 / 1000$ per heterosexual coital act. $^{29}$

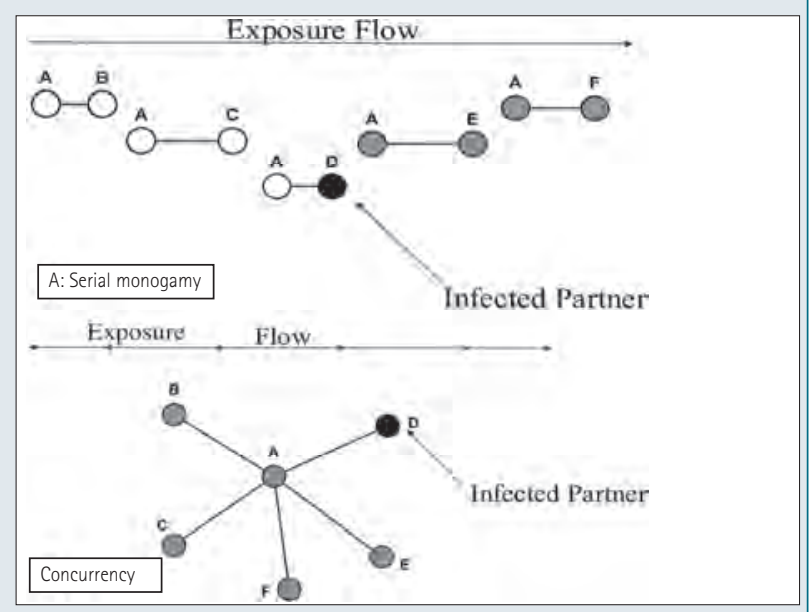

Fig. 2. In the serial monogamy scenario, after $A$ is infected by partner $D$, up to two partners are put at risk of HIV. In the concurrency scenario, all four other partners are placed at risk (black circle = HIV infected, grey circle = at risk of HIV infection) (figure based on Wohlfeiler and Potterat ${ }^{29}$ ).

Based on this type of evidence, concurrency-induced connected components have been argued to act as core-groups or 'superhighways' for the spread of HIV.

died of AIDS, feeling as if the future holds little or no opportunities, age of sexual debut, age difference with first partner and condom use at last sex all lose their significance in the multivariate analysis. Only female gender, ever having been or made someone pregnant, having experienced coercion or force during sex, partner concurrency, not mentioning 'limiting the number of sex partners' as an HIV prevention strategy and feeling generally unhappy remain as significant predictors of STIs on multivariate study (Table III).

TABLE I. RESPONSE RATES FOR WAVES 1, 2 AND 3 (RESPONSE RATES ARE IN PARENTHESES)

\begin{tabular}{|cllll} 
& \multicolumn{3}{c}{ Ethnic group } & \multicolumn{3}{c}{ Total } \\
\cline { 2 - 5 } Wave component & Blacks & Coloureds & Whites & $4752(89.6 \%)$ \\
Wave 1 completed interviews & $2126(93 \%)$ & $1879(87.5 \%)$ & $747(86 \%)$ & $3906(82.2 \%)$ \\
Wave 2 completed interviews & $1807(84.9 \%)$ & $1593(84.7 \%)$ & $506(67.9 \%)$ & $3536(75 \%)$ \\
Wave 3 completed interviews & $1519(71 \%)$ & $1680(84 \%)$ & $337(57 \%)$ & \\
\end{tabular}




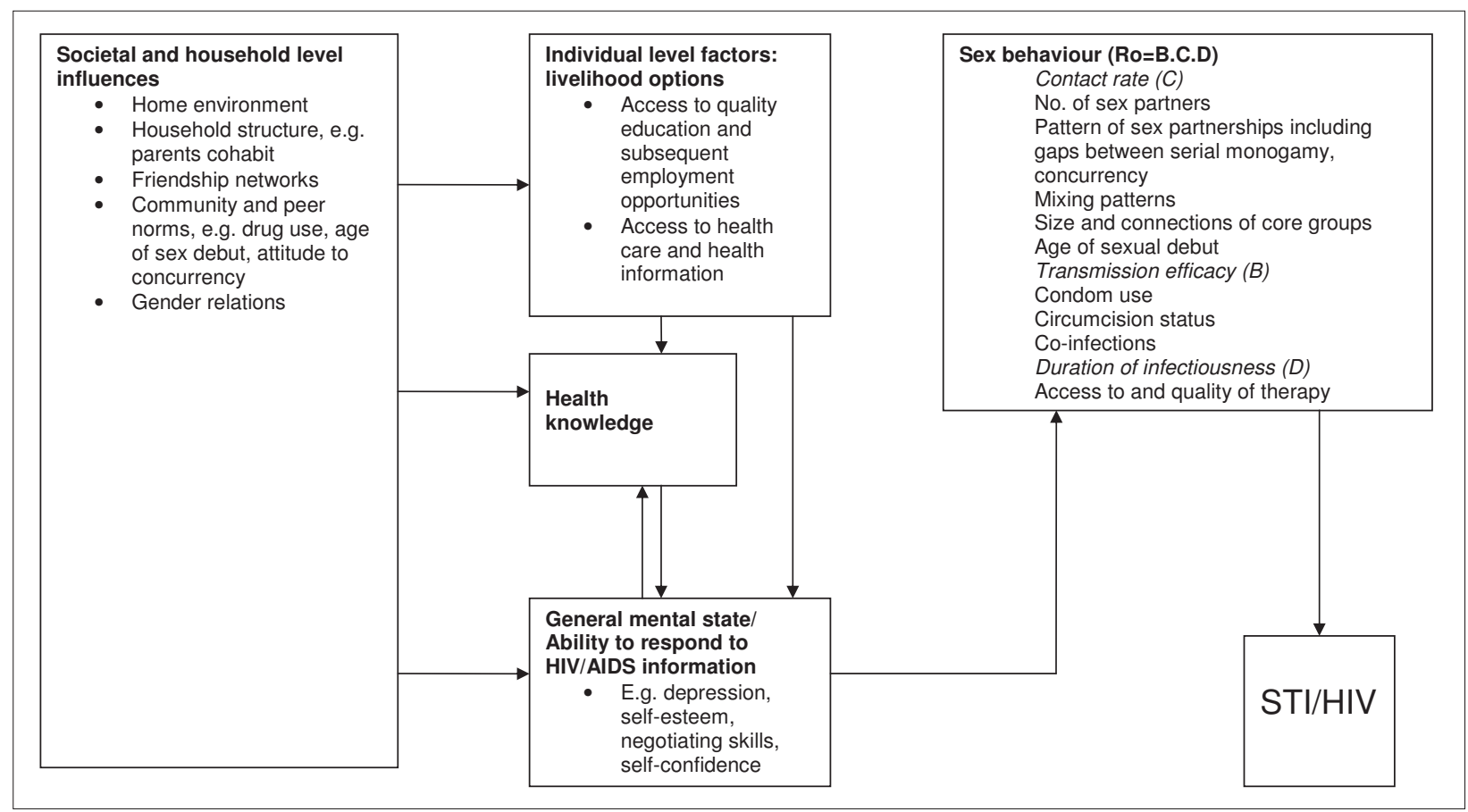

Fig. 3. Conceptual framework of the determinants of STI in young persons (based on Hallman ${ }^{20}$ ).

\section{DISCUSSION}

While there is extensive evidence linking concurrency to increased STI risk, most of this is from a developed world setting. To the best of our knowledge, this is the first study to reproduce these findings in an African setting. Of note, this analysis replicates the findings elsewhere that it is partner concurrency rather than respondent concurrency that facilitates STI spread. ${ }^{16}$ This is contrary to the findings of the four-cities study, which compared individual and ecological level risk factors in two high and two low HIV prevalence cities in Africa. Their finding was that levels of concurrency were not higher in the two high-prevalence cities. They did, however, find that there was a non-significant positive association between an individual's propensity to concurrency and HIV in the two high-prevalence cities (OR 2.02, $\mathrm{Cl} 0.84-4.88$ in Kisumu; OR 2.96, Cl 0.96 - 9.11 in Ndola). Numerous problems have been raised about this study.

1. It was a cross-sectional study approximately 15 years into the HIV epidemic, and the epidemic may therefore have altered behaviour (such as reducing concurrency rates) in the high-prevalence cities, which would result in a weakening or loss of any association between concurrency and HIV. This supposition is supported by the

\begin{tabular}{|c|c|c|c|c|}
\hline & \multicolumn{3}{|c|}{ Ethnic group } & \multirow{2}{*}{$\begin{array}{l}p \text {-value for difference } \\
\text { between the races }\end{array}$} \\
\hline & Black & Coloured & White & \\
\hline \multicolumn{5}{|l|}{ Wealth quintiles } \\
\hline 1 (poorest 20\%) & 47.7 & 13.4 & 1.2 & $<0.001$ \\
\hline 2 & 31.6 & 20.6 & 2.7 & $<0.001$ \\
\hline 3 & 12.5 & 26.1 & 0.3 & $<0.001$ \\
\hline 4 & 6.9 & 28.8 & 15.4 & $<0.001$ \\
\hline 5 (richest 20\%) & 1.4 & 11.2 & 80.4 & $<0.001$ \\
\hline \multicolumn{5}{|l|}{ Education level attained } \\
\hline Primary school education or less & 8.3 & 9.9 & 0.6 & $<0.001$ \\
\hline Grade 8 - 11 & 65.7 & 53.4 & 35.3 & $<0.001$ \\
\hline Grade 12 & 19.9 & 26.4 & 26.1 & $<0.001$ \\
\hline Post-secondary education & 6.1 & 10.4 & 38.0 & $<0.001$ \\
\hline$\%$ of families living below poverty line & 45 & 16 & 8 & $<0.001$ \\
\hline Mean age (yrs) & 20.89 & 20.56 & 20.06 & $<0.001$ \\
\hline$\%$ female & 55.0 & 53.4 & 53.7 & \\
\hline$\%$ married & 4.0 & 8.5 & 1.2 & $<0.001$ \\
\hline Mother currently employed & 30.0 & 48.6 & 75.8 & $<0.001$ \\
\hline Father currently employed & 41.9 & 64.3 & 88.1 & $<0.001$ \\
\hline Live with mother & 56.4 & 74.5 & 76.6 & $<0.001$ \\
\hline Live with father & 27.0 & 44.1 & 59.6 & $<0.001$ \\
\hline
\end{tabular}


TABLE III. UNIVARIATE AND MULTIVARIATE LOGISTIC REGRESSION MODEL FOR ASSOCIATION WITH SYMPTOMS OF STI IN 14 - 25-YEAR-OLDS IN CAPE TOWN

\begin{tabular}{|c|c|c|c|c|c|c|c|}
\hline \multirow[b]{2}{*}{ Factor } & \multirow[b]{2}{*}{ Category } & \multicolumn{3}{|c|}{ Univariate analysis } & \multicolumn{3}{|c|}{ Multivariate analysis } \\
\hline & & OR & $95 \% \mathrm{Cl}$ & $p$-value & OR & $95 \% \mathrm{Cl}$ & $p$-value \\
\hline Sex & Male & 0.42 & $0.27-0.66$ & $<0.001$ & 0.52 & $0.32-0.87$ & 0.014 \\
\hline Age & & 1.01 & $0.90-0.13$ & 0.911 & & & \\
\hline \multirow[t]{3}{*}{ Race } & Blacks & \multicolumn{6}{|c|}{ Reference group } \\
\hline & Coloureds & 0.74 & $0.49-1.13$ & 0.165 & 1.00 & $0.56-1.77$ & 0.988 \\
\hline & Whites & 0.09 & $0.02-0.55$ & 0.007 & 0.47 & $0.07-3.27$ & 0.450 \\
\hline \multirow[t]{4}{*}{ Income } & Quartile 1 (poorest) & \multicolumn{6}{|c|}{ Reference group } \\
\hline & Quartile 2 & 0.87 & $0.57-1.33$ & 0.533 & 0.91 & $0.56-1.48$ & 0.711 \\
\hline & Quartile 3 & 0.71 & $0.42-1.40$ & 0.202 & 0.87 & $0.47-1.63$ & 0.665 \\
\hline & Quartiles 4 \& 5 (richest) & 0.27 & $0.13-0.53$ & $<0.001$ & 0.66 & $0.30-1.45$ & 0.298 \\
\hline \multirow{4}{*}{$\begin{array}{l}\text { Education } \\
\text { (highest grade } \\
\text { attained) }\end{array}$} & Grade 0 - 7 & \multicolumn{6}{|c|}{ Reference group } \\
\hline & Grade 8 - 11 & 0.72 & $0.41-1.27$ & 0.268 & 0.66 & $0.35-1.25$ & 0.200 \\
\hline & Grade 12 & 0.41 & $0.23-0.79$ & 0.007 & 0.64 & $0.31-1.31$ & 0.221 \\
\hline & Post secondary & 0.32 & $0.12-0.82$ & 0.017 & 0.77 & $0.27-2.15$ & 0.619 \\
\hline $\begin{array}{l}\text { HIV prevention } \\
\text { knowledge }\end{array}$ & $\begin{array}{l}\text { Believe that limiting the } \\
\text { number of sex partners is a } \\
\text { way to decrease HIV risk }\end{array}$ & 0.11 & $0.03-0.34$ & $<0.001$ & 0.15 & $0.04-0.59$ & 0.006 \\
\hline $\begin{array}{l}\text { Affected by } \\
\text { HIV/AIDS }\end{array}$ & $\begin{array}{l}\text { Personally know someone } \\
\text { who has died of HIV/AIDS }\end{array}$ & 1.74 & $1.13-2.67$ & 0.012 & 1.31 & $0.81-2.10$ & 0.265 \\
\hline Alcohol & $\begin{array}{l}\text { Consumed alcohol in the } \\
\text { last month }\end{array}$ & 1.63 & $1.08-2.47$ & 0.019 & 1.16 & $0.72-1.89$ & 0.533 \\
\hline Mental state & $\begin{array}{l}\text { Feel unhappy about life in } \\
\text { general }\end{array}$ & 2.51 & $1.64-3.85$ & $<0.001$ & 2.14 & $1.35-3.40$ & 0.001 \\
\hline Opportunities & $\begin{array}{l}\text { Feel as if the future holds } \\
\text { poor or no opportunities }\end{array}$ & 1.40 & $1.16-1.69$ & $<0.001$ & 1.11 & $0.91-1.34$ & 0.306 \\
\hline Pregnancy & Ever pregnant & 2.91 & $1.92-4.41$ & $<0.001$ & 1.91 & $1.11-3.29$ & 0.019 \\
\hline Marital status & Married & 1.02 & $0.75-1.38$ & 0.89 & & & \\
\hline $\begin{array}{l}\text { Age of sexual } \\
\text { debut }\end{array}$ & Sexual debut $\leq 15$ years old & 1.41 & $0.98-2.08$ & 0.067 & 1.54 & $0.98-2.40$ & 0.056 \\
\hline Sex duress & $\begin{array}{l}\text { Have been forced to have } \\
\text { sex or threatened or hurt } \\
\text { during sex }\end{array}$ & 2.01 & $1.19-3.34$ & 0.008 & 1.90 & $1.08-3.31$ & 0.024 \\
\hline $\begin{array}{l}\text { Number of sex } \\
\text { partners }\end{array}$ & $\begin{array}{l}3 \text { or more lifetime sexual } \\
\text { partners }\end{array}$ & 1.04 & $0.66-1.65$ & 0.851 & & & \\
\hline $\begin{array}{l}\text { Age difference } \\
\text { with partner }\end{array}$ & $\begin{array}{l}\text { First sex partner } 4 \text { or more } \\
\text { years older }\end{array}$ & 1.64 & $1.09-2.48$ & 0.016 & 1.15 & $0.71-1.85$ & 0.559 \\
\hline $\begin{array}{l}\text { Partner } \\
\text { concurrency }\end{array}$ & $\begin{array}{l}\text { Any partner had concurrent } \\
\text { sexual relationship while } \\
\text { in relationship with the } \\
\text { respondent }\end{array}$ & 1.81 & $1.20-2.73$ & 0.005 & 1.60 & $1.02-2.49$ & 0.040 \\
\hline $\begin{array}{l}\text { Respondent } \\
\text { concurrency }\end{array}$ & $\begin{array}{l}\text { Respondent ever engaged in } \\
\text { two or more simultaneous } \\
\text { sexual relationships }\end{array}$ & 1.02 & $0.67-1.55$ & 0.941 & & & \\
\hline Condom use & Used condom at last sex & 1.58 & $1.08-2.12$ & 0.018 & 1.24 & $0.81-1.92$ & 0.323 \\
\hline
\end{tabular}

fact that the low HIV prevalence cities had considerably higher rates of the 'fragile STIs' - chlamydia and gonorrhoea - which are either self-limiting or easily treatable, whereas the high HIV prevalence cities also had higher rates of the other lifelong infection - herpes simplex virus $2 .{ }^{17}$ Taken together, these suggest that there have been behaviour changes that have led to reductions in recently acquired STIs in the high-prevalence cities.

2. Models predict that concurrency is important in the generation but not the maintenance of STI epidemics. ${ }^{6}$ The four-cities survey may have been too late in the genesis of the epidemic to pick up the generative effect of concurrency. 
3. The study only measured current concurrency, which may have led to an underestimate of concurrency. ${ }^{18}$

4. The much higher levels of circumcision in the low- as opposed to the high-prevalence cities may have provided such dramatic protection from HIV transmission as to obscure any relationship between concurrency and HIV transmission.

One way to get around some of these problems is to look at risk factors for STIs in adolescents, as their STIs are the result of relatively recent behaviours. A secondary data analysis of 4707 adolescents in the USA found that teens in concurrent relationships and serially monogamous relationships were 3.9 and 2.3 times respectively more likely to report an STI than teens who had only had a single relationship. ${ }^{19}$ The largest study to evaluate HIV prevalence and risk factors in South African youth found that the variable most strongly correlated with risk of HIV infection was race. ${ }^{12}$ Multivariate modelling revealed that black African females and males were 8.3 and 2.6 times respectively more likely to have HIV infection compared with the other races. What then are the factors that mediate these differences? The multivariate model included lifetime number of sexual partners, always using a condom with the most recent partner (which led to a significant reduction in HIV for women, but an insignificant reduction in men) and circumcision (the beneficial effect of which only just reached statistical significance). The study did not, however, measure concurrency. Our results suggest that the elevated STI rates in blacks may be related to higher concurrency rates; as in our study, the racial differential in STI symptoms found on univariate analysis disappeared in the multivariate analysis (which included partner concurrency).

The association of STI symptoms with female sex, ever having been pregnant and having experienced coercion or force during sex provides further evidence of the role that vulnerability and gender violence may be playing in the spread of STIs. Although socio-economic position lost its significance in multivariate modelling, it is of interest that feeling generally unhappy remained a risk factor for STI symptoms. This is not, to the best of our knowledge, a relationship that has been found in previous adolescent STI research, but as a measure of general mental state it may have considerable utility. One's general mental state impacts on how one accesses, integrates and operationalises safe sex messages and one's ability to negotiate with partners on these matters (Fig. 3)..$^{20}$ There is a notable body of qualitative research on sexual behaviour in South Africa and elsewhere in which respondents have pointed out that concerns about daily survival trump concerns about health consequences in 10 years' time. ${ }^{21,22}$ The CAPS data reveal a strong graded response between decreasing income and increasing levels of unhappiness. Being generally unhappy is likely to be a marker of persons who, owing to economic or other factors, are less able to access the necessary safe sex information and less likely to have the psychologi- cal and social support resources necessary to implement these messages.

Our study has certain limitations, the most significant of which was the fact that the symptoms of STI were gathered in wave 1 in 2002 and many of the sexual behaviour variables were gathered in wave 3 in 2005. Many of the variables gathered did however refer to the characteristics of the first sexual partner. Wherever possible we utilised the variable pertaining to the first sexual partner - for example, when evaluating the age gap between all previous partners we limited our variable to the age gap in the first sexual relationship. The effect of this study design should serve to dilute any relationship between the dependent and independent variables. We were also able to utilise the recently released data from wave 4 of the CAPS where individuals were asked if they had had an abnormal genital discharge or genital ulcer in the last 30 days. Because the reference period was only the last 30 days and not the last year as in wave 1, the proportion and numbers of symptomatic individuals (1.85\%) were too low for multivariate analyses. Individuals who noted symptoms of an STI in wave 1 were however more likely (4\%) to note STI symptoms in the month before wave 4 than individuals who had no STI symptoms in wave $1(1.6 \%)(p=0.06)$. This suggests that there is significant continuity in terms of the STI risk-promoting behaviours from wave 1 to wave 4 . The outcome variable was respondent-declared symptoms of STI, which was not necessarily corroborated by medical examination or microbiological or serological testing. While this makes the variable prone to both false-positive and false-negative results, it is a validated methodology that has been used in other STI epidemiological research. ${ }^{23}$ We are also unable to establish the direction of causation -it is therefore possible that it was the STI that made the individuals generally unhappy.

The high levels of concurrency found in this and related studies in southern Africa, the way that the patterning of concurrency and HIV so neatly overlap within the racial/ethnic sexual networks within this region (Kenyon C et al. - unpublished data) and the extensive evidence elsewhere linking concurrency to elevated STI transmission were sufficient grounds for UNAIDS to declare that concurrency was a major determinant of HIV transmission. By showing that partner concurrency is linked to STI symptoms, this study supports these findings. Much work now remains to be done to evaluate the link between HIV and concurrency in HIV-serolinked surveys with more complete network data, and to explore the upstream determinants of concurrency.

REFERENCES

Wellings $\mathrm{K}_{1}$ Collumbien $\mathrm{M}$, Slaymaker $\mathrm{E}$, et al. Sexual behaviour in context: a global perspective Lancet 2006: 368: 1706-1728.

2. Auvert B, Buvé A, Ferry B, et al.; for the Study Group on the Heterogeneity of HIV Epidemics in African Cities. Ecological and individual level analysis of risk factors for HIV infection in four urban populations in sub-Saharan Africa with different levels of HIV infection. AIDS 2001; 15: Suppl 4, S15-S30.

3. Koumans EH, Farley TH, Gibson JJ, et al. Characteristics of persons with syphilis in areas of persisting syphilis in the United States: sustained transmission associated with concurrent partnerships. Sex Transm Dis 2001; 28(9): 497-503. 
4. Ghani AC, Swinton SJ, Garnett GP. The role of sexual partnership networks in the epidemiology of gonorrhea. Sex Transm Dis 1997; 24(1): 45-56.

5. Potterat JJ, Zimmerman-Rogers $\mathrm{HZ}$, Muth SO, et al. Chlamydia transmission: concurrency, reproduction number, and the epidemic trajectory. Am J Epidemiol 1999: 150(12): 1331-1339.

6. Morris M, Kretzschmar M. Concurrent partnerships and the spread of HIV. AIDS 1997; 11(5): 641-648.

7. Lagarde $E_{1}$ Auvert $B_{1}$ Carael $M$, et al. Concurrent sexual partnerships and HIV prevalence in five urban communities of sub-Saharan Africa. AIDS 2001; 15(7): 877-884

8. Mah T. Concurrent sexual partnerships and HIV transmission in Khayalitsha, South Africa. Centre for Social Sciences Research Working Paper No. 225, August 2008, University of Cape Town.

9. Carael M. Sexual behaviour. In: Cleland JG, Ferry B, eds. Sexual Behaviour and AIDS in the Developing World. London: Taylor \&t Francis, 1995

10. Colvin M, Abdool Karim SS, Connolly C, Hoosen AA, Ntuli N. HIV infection and asymptomatic sexually transmitted infections in a rural South African community. Int J STD AIDS 1998; 9(9): 548-550.

11. Jewkes $R$, Dunkle $K$, Mduna $M$, et al. Factors associated with HIV seropositivity in young, rural South African men. Int J Epidemiol 2006; 35(6): 1455-1460.

12. Pettifor $A E$, Rees HV, Kleinschmidt I, et al. Young people's sexual health in South Africa: HIV prevalence and sexual behaviors from a nationally representative household survey. AIDS 2005: 19: 1525-1534

13. Quigley M, Munquti $K$, Grosskurth $H$, et al Sexual behaviour patterns and other risk factors for HIV infection in rural Tanzania: a case-control study. AIDS 1997; 11 237-248.

14. Carpenter L, Kamali A, Payne $M$, et al. Independent effects of reported sexually transmitted infections and sexual behaviour of HIV-1 prevalence among adult women, men and teenagers in rural Uganda. J Acquir Immune Defic Syndr 2002; 29: $174-180$

15. Lam D, Seekings J, Sparks M. The Cape Area Panel Study: Overview and Technica Documentation for Waves 1-2-3. Cape Town: University of Cape Town, December 2006.

16. Drumright LN, Gorbach PM, Holmes KK. Do people really know their sex partners? Sex Transm Dis 2004; 31(7): 437-442.
17. Marie-Claude B, Lowndes C, Gregson S. Population-level risk factors for HIV transmission and "the 4 cities study": temporal dynamics and the significance of sexual mixing patterns. AIDS 2002; 16(15): 2101-2102.

18. Mah TL, Halperin DT. Concurrent sexual partnerships and the HIV epidemics in Africa: Evidence to move forward. AIDS Behav 2008: Jul 22 (Epub ahead of print).

19. Kelley SS, Borawski EA, Flocke SA, et al. The role of sequential and concurrent sexual relationships in the risk of sexually transmitted diseases among adolescents. $J$ Adolesc Health 2003; 32: 296-305.

20. Hallman K. Gendered socioeconomic conditions and HIV risk behaviours among young people in South Africa. Afr J AIDS Res 2005; 4(1): 37-50.

21. Marks S. An epidemic waiting to happen? The spread of HIVIAIDS in South Africa in social and historical perspective. African Studies 2002: 61(1): 13-26.

22. Soul City, HIV prevention: multiple and concurrent sexual partnerships among youths and adults in South Africa. http://www.soulcity.org.za/programmes/ research/target-audience-research/soul-city-series/South_Africa_MCP_Report_ final.pdf (accessed 19 November 2008).

23. Manhart LE, Aral SO, King K. Sex partner concurrency measurement, prevalence, and correlates among urban 18 - 39-year-olds. Sex Transm Dis 2002- 29(3): 133-143.

24. Wawer MJ, Gray RH, Sewankambo NK, et al. Rates of HIV-1 transmission per coital act, by stage of HIV-1 infection, in Rakai, Uganda. J Infect Dis 2005; 191(9): 14031409

25. Pinkerton SD. Probability of HIV transmission during acute infection in Rakai, Uganda. AIDS and Behavior 2008; 12(5): 677-684.

26. Pilcher $\mathrm{CD}$, Tien $\mathrm{HC}$, Eron J, et al. Brief but efficient: acute HIV infection and the sexual transmission of HIV.J Infect Dis 2004: 189: 1785-1792.

27. Halperin DT, Epstein H. Why is HIV prevalence so severe in southern Africa? The role of multiple concurrent partnerships and lack of male circumcision: Implications for AIDS prevention. Southern African Journal of HIV Medicine 2007; issue 26 (March):19-23.

28. Kretzschmar Mi Morris M. Measures of concurrency in networks and the spread of infectious disease. Math Biosci 1996: 133(2): 165-195.

29. Wohlfeiler D, Potterat BA. Using gay men's sexual networks to reduce sexually transmitted disease/human immunodeficiency virus transmission. Sex Transm Dis $2005 ; 32(10):$ Suppl, s48-52

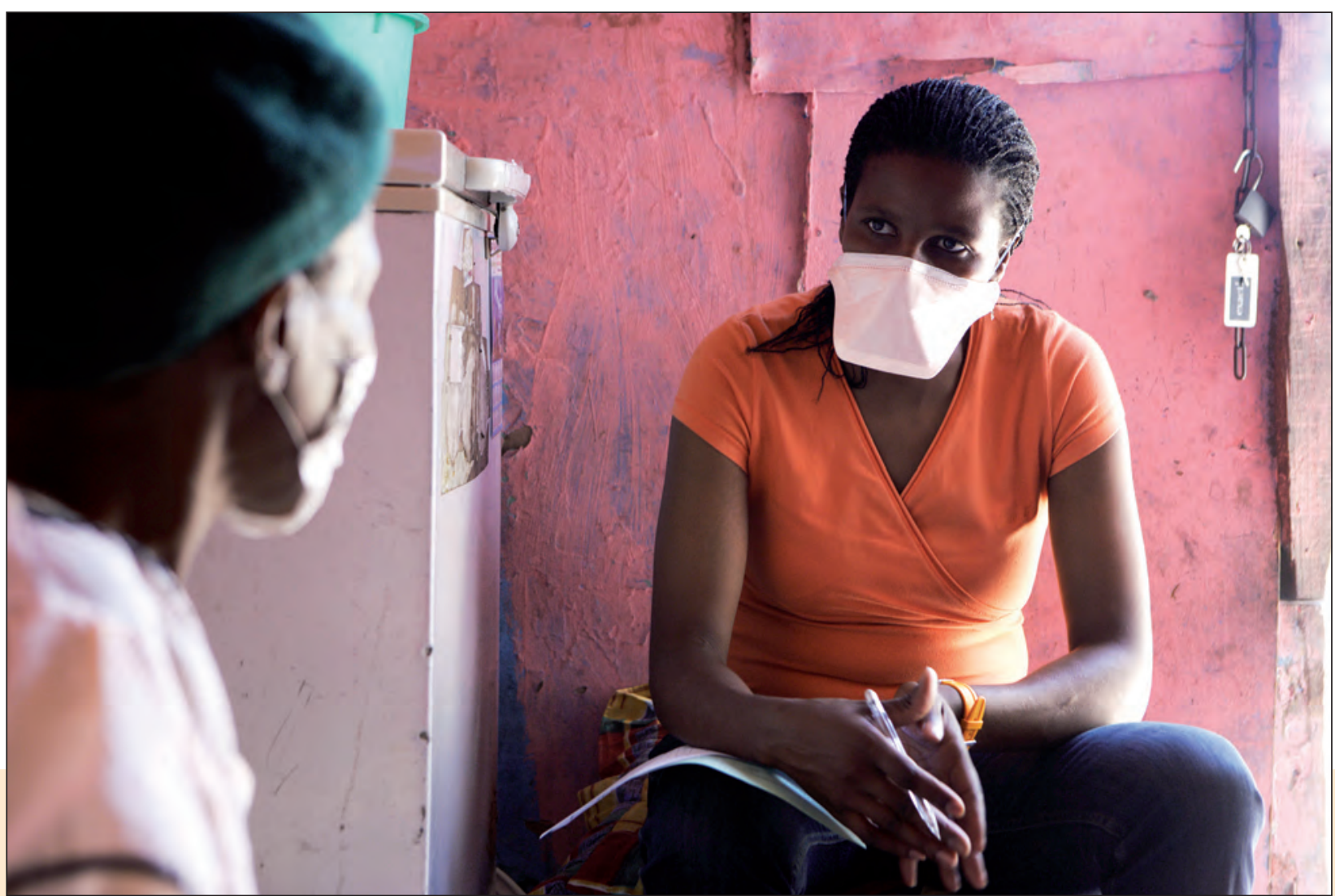

This woman found out she had MDR-TB while she was pregnant, and later the baby was also diagnosed. Despite considerable challenges she and her daughter managed to complete the two years of MDR-TB treatment, both of them are now healthy, and she is working for Médecins sans Frontiers in Khayelitsha as a community health worker. 